\title{
Impact of Consumer Environmental Consciousness on Consumer Perceived Value from Sharing Economy
}

\author{
Agne Gadeikiene, Asta Svarcaite
}

\author{
Kaunas University of Technology \\ K. Donelaicio st. 73, LT-44029, Kaunas, Lithuania \\ E-mail.agne.gadeikiene@ktu.lt,asta.svarcaite@ktu.lt \\ cross $^{\text {ref }}$ http://dx.doi.org/10.5755/j01.ee.32.4.28431
}

\begin{abstract}
The intensive spread and the growth of the sharing economy challenge the sharing platforms to attract and retain consumers. Thus, a comprehensive understanding of consumers' perceived value and marketing strategy oriented to value growth is becoming essential both from the scientific and practical point of view. However, in the scientific literature, the construct structure of consumer perceived value from sharing economy and the factors that determine it are not sufficiently explored. To fill this gap, this study aims to investigate consumer perceived value from sharing economy and explore how it is influenced by consumer environmental consciousness and consumer attitude towards sharing platforms. Based on the quantitative research findings, it was found that consumer environmental consciousness has a significant direct effect on attitude towards sharing economy platforms and directly influences consumer perceived social value. The results of this study confirm the mediating effect of the consumer attitude toward sharing platforms in the relationship between consumer environmental consciousness and consumer perceived economic, functional, emotional value from sharing economy.
\end{abstract}

Keywords: Sharing Economy; Sharing Platform; Environmental Consciousness; Consumer Perceived Value; Economic Value; Functional Value; Social Value; Emotional Value.

\section{Introduction}

Sharing economy phenomenon is already known for more than a decade (Bucher et al., 2016; Dabbous \& Tarhini, 2019; Mont et al., 2020), and it has been analysed from different perspectives. A number of studies are dedicated to searching for the standard description of the sharing economy phenomenon that would suit different management and economics research fields (Mont et al., 2020; Gurau \& Ranchhod, 2020). Sharing economy market increases every year; for example, in the US market, there are prognoses that by 2025 the revenue will reach US $\$ 335$ billion (PwC, 2015; Sands et al., 2020), and every year a significant number of new consumers will join the sharing economy (Lock, 2019). PwC (2016) predicts that the value of sharing economy platform transactions in Europe will increase 20 times and will reach the amount of 570 billion EUR by 2025. Fast technological development, digital progress, urbanization, financial motives, and increasing focus on sustainability and environmental issues are the main factors that promote the emergence, development, and growth of the sharing economy (Basselier et al., 2018). The sharing economy's growth stimulates the need for more scientific research related to the sharing economy phenomenon. The sharing economy is mostly analysed from the consumer's perspective (Hamari et al., 2016; Sung et al., 2018; Lee et al., 2018; Zhang et al., 2019), business perspective (Schwanholz \& Leipold, 2020; Mont et al., 2020; Curtis \& Mont, 2020), and government perspective (Bernardi \& Diamantini, 2018; Mont et al., 2020). New scientific investigations may help the sharing economy stakeholders to gain a better understanding of this phenomenon operating principle, develop their business more efficiently, and gain a competitive advantage. Up to date, it is still unclear why sharing platforms face challenges in attracting and retaining a sufficient number of loyal consumers (Clauss et al., 2018). Increasing consumer perceived value can be one of the possible sources of competitive advantage for sharing platforms. Consumer perceived value from sharing economy is related to the overall evaluation of the service, tangible and intangible benefits consumer gains. It affects consumer satisfaction and future intentions related to sharing platform services (Zhang et al., 2019). Thus, a comprehensive understanding of consumers' perceived value and marketing strategy oriented to the increase of consumer perceived value is becoming a priority both from the scientific and practical point of views. However, in the scientific literature, the structure of consumer perceived value from sharing economy and the factors that determine it are not sufficiently explored (Dabbous \& Tarhini, 2019; Zhang et al., 2019; Laukkanen \& Tura, 2020). Most of the attention is paid to analysing business models, strategies and conceptualising the sharing economy phenomenon (Agarwal \& Steinmetz, 2019).

The sharing economy stakeholders' behaviour studies have identified benefits that consumers receive from sharing platforms (Hamari et al., 2016; Lee at al., 2018; Zhang et al., 2019; Sung et al., 2018). Based on these studies, this paper analyses two aspects of sharing economy: first, consumer environmental consciousness as an aspect of sustainability; second, consumer perceived value from sharing economy that results from the sharing platform usage. In the scientific literature, researchers emphasize that sharing platforms have a high potential for environmental sustainability (Hamari et al., 2016; Munoz \& Cohen, 2017; Laukkanen \& Tura, 2020). For example, $76 \%$ of the US 
respondents agree that sharing economy is better for the environment, and $78 \%$ believe that sharing economy reduces waste $(\mathrm{PwC}, 2015)$. However, there is a lack of studies that investigate this aspect from a consumer perspective. Thus, we argue that environmentally conscious consumers would perceive higher value from sharing economy. Although most sharing platform developers emphasize economic and functional (platform-related) benefits for consumers from sharing economy, we argue that it allows creating a much broader range of consumer benefits, including social and emotional outcomes.

Considering the above mentioned, this study aims to investigate consumer perceived value from sharing economy and explore how it is influenced by consumer environmental consciousness and consumer attitude towards sharing platforms.

We will provide a theoretical overview of the sharing economy phenomenon and analyse consumer perceived value from sharing economy. We will empirically test how the consumer environmental consciousness and attitude to sharing platform impact consumers' perceived value from sharing economy. Finally, conclusions, discussion, and implications for further research will be provided. We assume that this research and its results will give a better understanding of the sharing economy phenomenon from a consumer perspective and will add value to the research stream focusing on the sharing platform value proposition and business model development. Besides that, it emphasizes the sustainability aspect of the sharing economy that might be a strong motive for encouraging consumers to engage in the sharing economy platform services. This study contributes to the new research stream, seeking to understand consumer motives to engage in sharing economy and investigating its benefits from a consumer perspective. It provides arguments to consider consumer perceived value from sharing economy as an outcome of consumer environmental beliefs and attitude formed after a concrete experience with a particular sharing platform.

\section{Theoretical Background}

\section{Sharing Economy at a Glance}

The definition of the sharing economy is unambiguous and still has different interpretations. Munoz \& Cohen (2017) define the sharing economy as "a socio-economic system enabling an intermediated set of exchanges of products and services between individuals and organizations which aim to increase efficiency and optimization of sub-utilized resources in society". According to Miller (2019), the sharing economy is a business model in which individuals or companies share products, services, space, or money. Other authors (Belk, 2014; Mitchell \& Thierer, 2015) describe these resources as underused assets that can be shared with others. Unlike usual, Koopman et al. (2015) and Cockayne (2016) describe the sharing economy through digital platforms that bring consumers together in the online space and create networks to share products and services. Although the scientists describe the concept of sharing economy differently, there are also common criteria in these definitions. One of them is that the sharing economy provides temporary access to certain underused assets (Choi et al., 2014; Lee \& Kim, 2018), including skills and knowledge, in exchange for financial or social benefits (Botsman \& Rogers, 2010; Sung et al., 2018).

Otherwise, the principle of sharing is not new, and it was common to share items between family members, friends or neighbours, and so on (Belk, 2014; Mont et al., 2020). As digital technologies emerged into the sharing economy, interest in this economic phenomenon grew, and the popularity of sharing increased significantly (Bucher et al., 2016; Zhang et al., 2019). The sharing economy has begun to expand in the areas such as accommodation (e.g., Airbnb) and mobility (e.g., Mobike, CityBee, Uber), then it has spread to such business areas as food (e.g., OLIO), finance (e.g., SAVY), fashion (e.g., Reheart), etc. In addition, a diversity of personal and professional services have been offered through sharing platforms. In this sense, the phenomenon has expanded traditional business concepts (Hamari et al., 2016; Munoz \& Cohen, 2017; Zhang et al., 2019).

There are three main stakeholders identified in the sharing economy: consumers, suppliers, and controllers/platforms (Akhmedova et al., 2020; Wirtz et al., 2019). Sands et al. (2020) distinguished three types of sharing consumers who engaged with sharing platforms: the mobility-focused sharer, the diverse-platform sharer, the power-platform sharer. All these types of consumers in the sharing economy have different motivations, attitudes, and behaviour toward sharing economy (Sands et al., 2020). A supplier can be a resource owner who provides an asset, service, or knowledge via sharing platform to be accessed by a resource consumer (Curtis \& Mont, 2020). In scientific literature, a supplier's role as a stakeholder in the sharing economy is still little analysed. Digital technology or sharing platform plays a vital role in sharing economy operating principle. Wirtz et al. (2019) emphasize the importance of sharing platforms in the sharing economy as they offer short-term access to resources that are the platform's or its members' property and, thus, play an important role as intermediary between the asset owner and its user. According to Acquier et al. (2019), sharing platforms can be analysed regarding what value they offer and how that value is created. According to the business model, sharing platforms can be divided into four groups (Acquier et al., 2019): Shared infrastructure providers, Community-based platforms, Mission-driven platforms, and Match-makers. All these types of platforms have specific internals and create value for consumers. Consumer experience with a particular sharing platform results in his/her attitude towards the platform that leads toward consumer perceived general value from sharing economy.

\section{Consumer Perceived Value from Sharing Economy}

In the scientific literature, consumer perceived value is defined similarly. Authors (Petrick, 2002; Kuo et al., 2009) define it as the consumer's assessment, perception, or comparison between what benefits were got and costs experienced. Kuo et al. (2009) state that consumers' perceived value is experienced during or after consuming a product or service. Zhang et al. (2019) emphasize that the consumer perceives value only when the benefits of 
consuming a product or service outweigh the costs incurred. A slightly different definition is suggested by Smith \& Colgate (2007). They point out that perceived value is the consumer's preference for those products or services features or usage of which facilitate the achievement of consumer goals and needs. According to these definitions, the perceived consumer value can be defined as the benefits a consumer perceives during or after consumption in exchange for the costs incurred or resources consumed.

A broad approach towards consumer perceived value leads to dividing it into utilitarian and hedonic value; in some studies, the symbolic value is also singled out (Smith \& Colgate, 2007; Hwang \& Griffiths, 2017). The symbolic value is associated with positive consequences of shared consumption, such as altruism and social values (Hwang \& Griffiths, 2017). According to Hwang \& Griffiths (2017), the utilitarian value is created from a functional and objective consumer experience; for example, the sharing of underused resources in a sharing economy can be identified as a utilitarian benefit. In contrast, the hedonic value perceived by consumers arises from the emotional experience of consuming a product or service (Bucher et al., 2016). For example, participation in a sharing economy gives pleasure and social interaction to consumers. According to Lee \& Kim (2018), consumer perceived hedonic value includes the uniqueness of a product or service or the emotional connection it causes to the consumer. Meanwhile, the utilitarian value is associated with effective, specific tasks or economic aspects of products or services. Lee \& Kim (2018) found that the consumer perceived hedonic value from the sharing economy positively affects consumer satisfaction and loyalty.

While seeking to understand better the consumer perceived value from sharing economy, the scientific literature provides a more detailed breakdown of it into dimensions. In the scientific literature, different dimensions of consumer perceived value are found. For example, Petrick (2002) identified the value of reputation, defined as the prestige or status of a product or service perceived by the consumer. Hamari et al. (2016) included reputation in their research model as one of the factors motivating consumers to participate in the sharing economy. Shanker (2012) disaggregated consumer perceived value as brand and co-creation value. According to the author, the consumer perceives the brand value due to consuming a product or service bearing a brand that provides a relevant experience. The co-creation value is related to the company's consideration and adaptation to the consumer's individual needs. Consumers understand this value as an opportunity to participate in the process of developing a product, service, or brand (Shanker, 2012).

As the above analysis shows, there are quite many research attempts to find a specific dimensional structure of consumer perceived value from sharing economy. In this paper, we argue that it is worth applying a widely acknowledged approach to the construct structure of consumer perceived value in the case of sharing economy. Up-to-date research in different fields confirms that consumer perceived value consists of four dimensions functional value, economic value, social value, and emotional value (Smith \& Colgate, 2007; Hamari et al.,
2016; Sung et al., 2018; Dabbous \& Tarhini, 2019; Zhang et al., 2019).

Functional value is associated with the perceived usefulness of a product or service to the consumer and meets his primary purpose of using the product or service and helps to create value (Shanker, 2012; Smith \& Colgate, 2007). According to Zhang et al. (2019), consumers perceive the functional value of sharing economy through various technical and functional aspects such as convenience, location, time, flexibility, reliability, effectiveness, etc. In the scientific literature, the functional value can be termed a technical value that essentially means exactly the same thing (Smith \& Colgate, 2007; Shanker, 2012).

Economic value includes the maximum amount of money, efforts, time, and other resources a consumer must devote to obtain a particular product or service (Kim \& Tang, 2020). Zhang et al. (2019) state that economic value is the most important in the sharing economy, and the popularity of sharing platforms has increased primarily due to economic value. Besides, the concept of economic value can be used synonymously as the value of costs (losses) (Smith \& Colgate, 2007; Shanker, 2012). Economic value, which covers all the costs incurred and resources used by the consumer, can be divided into the monetary price and behavioural price or quality dimensions (Petrick, 2002; Kuo et al., 2009). The monetary price is defined as the actual price of the product or service, and the behavioural price includes all other costs associated with the purchase of the product or service, such as the consumer's efforts and time spent (Petrick, 2002; Hamari et al., 2016).

Social value is the establishment of social connections or the search for like-minded people. It is also considered an important outcome of sharing economy (Bucher et al., 2016; Sung et al., 2018; Zhang et al., 2019). There are many aspects of social value arising from activities in the sharing economy, such as making friends with other platform members or service providers, high trust and satisfaction, and so on (Zhang et al., 2019). This value is also experienced when products and services have a particular social significance for the consumer and increase his social self-awareness (Kuo et al., 2009). It was also observed that the value of the relationship is related to the social value, which is interpreted as the mutual benefits created by the peer-to-peer relationship (Hamari et al., 2016), the strengthening of interrelationships, and a sense of satisfaction (Shanker, 2012; Kim \& Tang, 2020). According to Shanker (2012), the social value can be added through a consumers' relationship with a company, for example, quality of service, delivery efficiency, or supplier knowledge.

Emotional value describes the consumer's feelings when consuming a product or service (Hamari et al., 2016; Lee \& Kim, 2018; Zhang et al., 2019). This value can be linked to the added value that consumers receive as it encourages consumer loyalty and participation in loyalty programs (Zhang et al., 2019). This value is based on the fact that participation in the sharing economy provides a pleasant and exciting experience, especially when interacting with different people (Hamari et al., 2016). 
Emotional value is also related to an emotional response (Pertick, 2002), experiential outcomes that describe experiences, feelings, or emotions generated by the use of a product or service (Smith \& Colgate, 2007), and individual benefits that are associated with induced consumer actions or behaviours (Kim \& Tang, 2020).

Relationship between Consumer Environmental Consciousness, Attitude to Sharing Platform, and Consumer Perceived value from Sharing Economy

Consumers' attitudes towards products or services and purchase decisions can be affected by their personal values and beliefs (Huang et al., 2014). Responsible purchasing, green behavior, eco-friendly products, sustainable consumption are terms that are used to discuss environmentally responsible consumption. Nowadays, consumers are more concerned about the environment and how their consumption can affect it. Huang et al. (2014) validated their research hypothesis that environmental consciousness positively influences green consumer behaviour. Kumar et al. (2020) identified that young consumers are willing to pay a higher price if they understand the environmental benefit. Thus, the same thoughts or repetitive attitudes toward the effect of consumption on the environment and nature as a whole that affect an individual's resulting behaviour may be termed as environmental consciousness (Samdahl \& Robertson, 1989; Zimmer et al., 1994; Huang et al., 2014). Certain beliefs influence attitudes, and then attitudes influence consumption behaviour.

Most of the articles state that sharing economy contributes to more sustainable consumption (Hassanli et al., 2019; Martin, 2016; Heinrichs, 2013). Consumption level and the demand for new products can be reduced when products are used not owning them (Seegebarth et al., 2016; Belk, 2014). Curtis \& Mont (2020) explain that the sharing economy provides high sustainability possibilities, but it is not sustainable by itself (Ma et al., 2019). However, the key role for sustainable consumption depends on adequate social, economic and political environments (Martin, 2016; Cooper \& Timme, 2015). For example, greater durability or less waste and emission over product lifetime can be identified as advantages in terms of sustainable consumption (Ma et al., 2019). In their research, Sands et al. (2020) noted that most of the sharing platforms advertise as environmentally friendly and sustainable, but there is no empirical evidence that proves this statement. Researchers confirmed by their empirical study that consumer environmental motivation positively impacts participation in the sharing economy (Sands et al., 2020). Parguel et al. (2017) claim that environmentally conscious consumers are more willing to responsible consumption and perceive the higher value of the sharing economy. Research by Hamari et al. (2016) supports that consumers who are more environmentally conscious are more involved in the sharing economy, and perceived sustainability positively influences its value perception. Based on the above discussion, the following hypothesis was formulated:

Hypothesis H1. Consumer environmental consciousness has a positive impact on consumer perceived value from sharing economy.
According to researchers (Hamari et al., 2016; Sung et al., 2018), perceived pleasure, enjoyment benefits are related to consumer attitude towards sharing platform. As an example, Sung et al. (2018) bring Airbnb accommodation platform that provides consumers with an unexpected and unique experience. For consumers using sharing platforms' services, the satisfaction is enhanced by an exciting and engaging experience (Hamari et al., 2016). In the explanations above, the similarity between pleasure and enjoyment benefits and emotional value dimension is recognizable.

In their research, Sung et al. (2018) noticed that the network effect benefit is associated with consumer attitude towards the sharing platform. The sharing economy operates by bringing together many consumers and suppliers in a single sharing platform. This network effect provides consumers with a wide choice of products or services offered, significantly increasing benefits and perceived value to the consumer himself (Sung et al., 2018). The parallel between the network effect and consumer perceived social value dimension is noticed. Shanker (2012) explains that social value can be gained through a relationship with a company and various relationships that emerge at the beginning, during the process, or at the end of product purchase. Bucher et al. (2016) distinguish social motives that significantly related to consumer attitude towards sharing economy. Social motives are described as the desire to make new social connections, be part of the community, and find like-minded people (Bucher et al., 2016).

According to Bucher et al. (2016), Hamari et al. (2016), Sung et al. (2018), financial, economic benefits from participation in the sharing economy are associated with reducing costs or saving money through temporary access to resources. This explanation has a similarity with the description of consumer perceived economic value from sharing economy. Hamari et al. (2016) also singled out economic benefits that may influence the attitude towards collaborative consumption. However, the research results showed that perceived economic benefits do not affect attitudes. Thus, it is worth to test the other way impact of consumer attitude to sharing platform on perceived economic value from sharing economy.

Hamari et al. (2016) identify perceived platform reputation as a factor that influences the general consumer attitude to sharing economy. The reputation of a sharing platform provider or sharing platform itself can be a strong external factor influencing consumer engagement in the sharing economy (Lee et al., 2018). Dabbous \& Tarhini (2019) emphasize that trust with the platform plays a vital role in the sharing economy, and lack of trust can create barriers for consumers to participate in it. Trust in the platform is reflected in consumer attitude to the sharing platform and leads to consumers' perception of benefits from participating in the sharing economy (Lee et al., 2018). Reliability is identified as one of the functional aspects of the sharing platform that is directly related to consumer perceived functional value from sharing economy (Zhang et al., 2019).

The above literature analysis shows that there is a link between consumer attitude to sharing platform and consumer perceived value from sharing economy. However, 
there are different interpretations of whether consumer perceived value is an outcome or an antecedent of the attitude. In this paper, we assume that consumer perceived value from sharing economy is possible only when a consumer has a positive attitude towards a particular sharing platform, i.e., we consider that consumer perceived value from sharing economy is an outcome of attitude. Such a relationship is being confirmed in other research domains (for example, Moliner-Velazquez et al. 2014; ChartonVachet et al., 2020). Based on these arguments, the following hypothesis is proposed:

Hypothesis H2. Consumer attitude towards sharing platform has a positive impact on consumer perceived value from sharing economy.

Researchers (Bucher et al., 2016; Hamari et al., 2016) determine the consumer sustainability and moral beliefs that significantly affect consumer attitude towards sharing platforms. Co-consumption reduces negative environmental impacts, so environmental consciousness can be an important factor for choosing sharing platforms for consumers who care about nature and its protection (Hamari et al., 2016; Sung et al., 2018). Moral motives are based on the fact that sharing is a more sustainable and greener alternative to the traditional business that promotes altruism, community support, sustainability, and conscious consumption (Bucher et al., 2016), i.e., increases consumer perceived value from the sharing economy. This paper argues that a positive consumer attitude towards sharing platforms strengthens the impact of consumer environmental consciousness on consumer perceived value from sharing economy. The similar mediating effect of attitude to a particular object in the relationship between consumer environmental beliefs and perceived value or purchase intentions is confirmed in different studies. For example, Paul et al. (2016) confirmed that consumer attitude to green product purchase mediates the relationship between consumer environmental concern and green product purchase intentions. Similarly, Ogiemwonyi et al. (2020) research confirmed the mediating effect of environmental attitude in the impact of green environmental awareness and green culture. From the literature above, it can be inferred that the attitude towards sharing platforms may be investigated as an intermediary construct in the relationship between consumer environmental consciousness and consumer perceived value from sharing economy. So the following hypothesis:

Hypothesis H3. Consumer attitude toward sharing platform mediates the relationship between consumer environmental consciousness and consumer perceived value from sharing economy.

\section{Research Design}

Method and sample. For hypothesis testing, the quantitative approach was adopted, and a method of questionnaire survey was used to collect the data. As we study consumers of the sharing economy, our general research population was adult people who have used the sharing platform at least once. An online survey was launched using the SurveyMonkey platform and disseminated through various channels in November 2020.
Measures. At the beginning of the survey, the sharing economy and sharing platform definitions were presented: "A sharing economy is a model of the economy where people share assets and receive financial or social benefits. The sharing economy is most prevalent in the accommodation, transportation, and financing sectors. Sharing platform - a digital platform (website, an app on the phone, etc.) that mediates the sharing process, i.e., providing temporary access to a service or product". Then the respondents were asked to answer identification questions to determine their eligibility to participate in the research. Respondents were presented with the list of activities related to sharing economy and asked to indicate the frequency of engagement in each activity. Next, they were asked to indicate their agreement with the statements related to environmental consciousness, attitude toward sharing platform, and the perceived value from the sharing economy. Environmental consciousness was measured by a three-item scale, adapted from Bucher et al. (2016) and Parguel et al. (2017). A six-item scale was used to measure attitude towards sharing platform, and the scale was composed following Bucher et al. (2016), Hamari et al. (2016), Sung et al. (2018), and Dabbous \& Tarhini (2019). Consumer perceived value was measured by distinguishing each dimension separately. The economic value was measured by a three-item scale, adapted from Bucher et al. (2016), Hamari et al. (2016), and Dabbous \& Tarhini (2019). For the measurement of functional value, the six items scale was created according to Smith \& Colgate (2007), Lee et al. (2018), and Zhang et al. (2018). Social value was measured by a five-item scale adapted from Bucher et al. (2016). And for the measurement of emotional value five-item scale was created based on Hamari et al. (2016), Sung et al. (2018), Lee et al. (2018), and Zhang et al. (2018). A five-point Likert scale was used for each item, ranging from 1 ("Totally disagree") to 5 ("Totally agree"). Finally, respondents were asked to provide their demographic information.

\section{Research Results}

Respondent characteristics. All the respondents were from Lithuania and the sharing economy platform consumers. At the end of the data collection period, 243 responses were collected, 54 excluded as uncompleted responses, 26 respondents were rejected as ineligible because they had never participated in the sharing economy. Assessing the low number of consumers of the sharing economy in Lithuania (European Commission, 2018; Spinter research, 2018) and the sharing economy platforms' market revenue performance under EU-average (European Commission, 2018) also the prevalence of sharing platforms only in large Lithuanian cities, as well as the target consumers selected during the survey, the sample size is considered as sufficient to examine the relationships between the constructs.

The demographic profile of the respondents is shown in Table 1. Of the 163 respondents, 42 were male, 119 female, and 2 preferred not to specify their gender. A majority of respondents were young adults, with $36.2 \%$ aged $30-39$ and $30.1 \%$ aged 20-29. Regarding the number of household members, most of the respondents were from four persons in the household, and it is $39.3 \%$. 
Table 1

Demographic Profile of the Respondents

\begin{tabular}{|l|l|c|c|}
\hline Characteristic & \multicolumn{1}{|c|}{ Values } & Frequency & \% \\
\hline Gender & Female & 119 & 73.0 \\
& Male & 42 & 25.8 \\
& not specified & 2 & 1.2 \\
\hline Age group & up to 19 years & 5 & 3.1 \\
& 20-29 years & 49 & 30.1 \\
& 30-39 years & 59 & 36.2 \\
& 40-49 years & 42 & 25.8 \\
& 50 years and more & 8 & 4.9 \\
\hline Household size & One person & 26 & 16.0 \\
& Two persons & 34 & 20.9 \\
& Three persons & 29 & 17.8 \\
& Four persons & 64 & 39.3 \\
& Five or more persons & 10 & 6.1 \\
\hline Average & up to 399 Eur & 37 & 22.7 \\
individual & 400-799 Eur & 29 & 17.8 \\
monthly & 800-1199 Eur & 45 & 27.6 \\
income & 1200-1599 Eur & 36 & 22.1 \\
& 1600 Eur or more & 16 & 9.8 \\
\hline
\end{tabular}

Note: $N=163$

Data analysis. The first step in the data analysis was to evaluate the validity and reliability of the construct measurements. Since the measurement scales were adapted from other authors to the research context, we started with exploring the construct structures. For this purpose, we applied exploratory factor analysis (method: principal component; rotation: Varimax). The survey data was analysed using IBM SPSS Statistics 25.
Table 2 shows constructs of consumer environmental consciousness and attitude to sharing platforms are onedimensional. The latent construct of consumer perceived value from sharing economy, as presumed after the theoretical analysis, consists of four dimensions (four factors were extracted): economic value, functional value, social value, and emotional value. Four items were eliminated due to the low factorial weight: "Using sharing economic platforms saves me time"; "My friends, acquaintances use sharing economic platforms"; "I always review feedback before making a deal on a sharing economy platform"; "I have a unique experience using sharing economic platforms". Each construct explained no less than $65 \%$ of the total variance (see AVE column for details in Table 2); item factorial weights were also quite high. KMO test values for each factor analysis allow stating that they were adequate. For evaluating the internal consistency validity and reliability of the constructs, the Cronbach's alpha and composite reliability (CR) coefficients were calculated for each scale. They demonstrated a high level of internal consistency and reliability (see Table 2).

For evaluating the constructs' discriminant validity, AVE's square roots and correlations among constructs were calculated and compared (see Table 3). The square roots of AVE for each latent construct are presented on the diagonal. As can be seen from Table 3, they are greater than correlations with other latent variables, which indicates that the scale has a satisfactory level of discriminant validity.

Structure of the Research Constructs: Results of Factor Analysis, Reliability, and Validity Measures

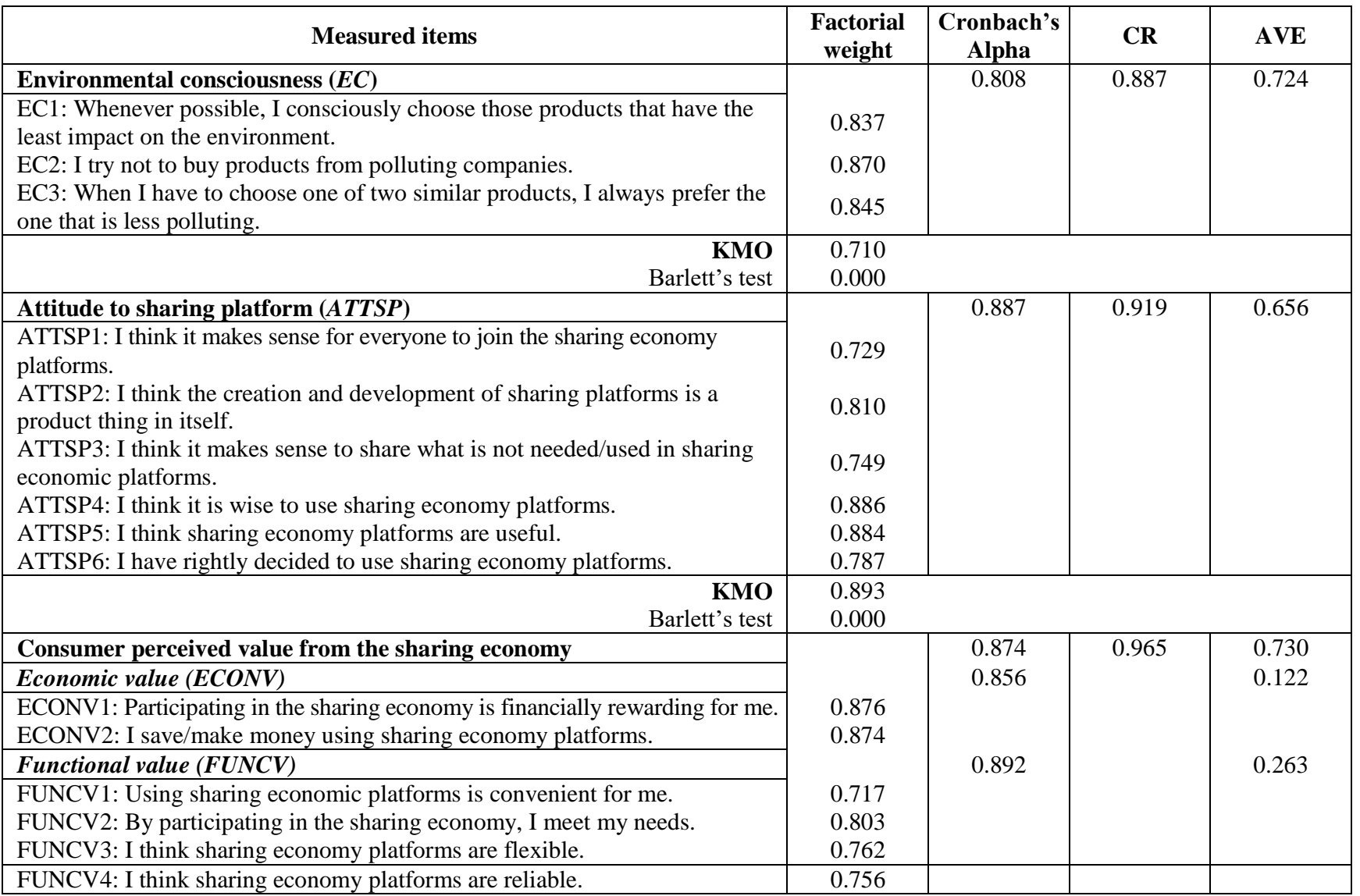




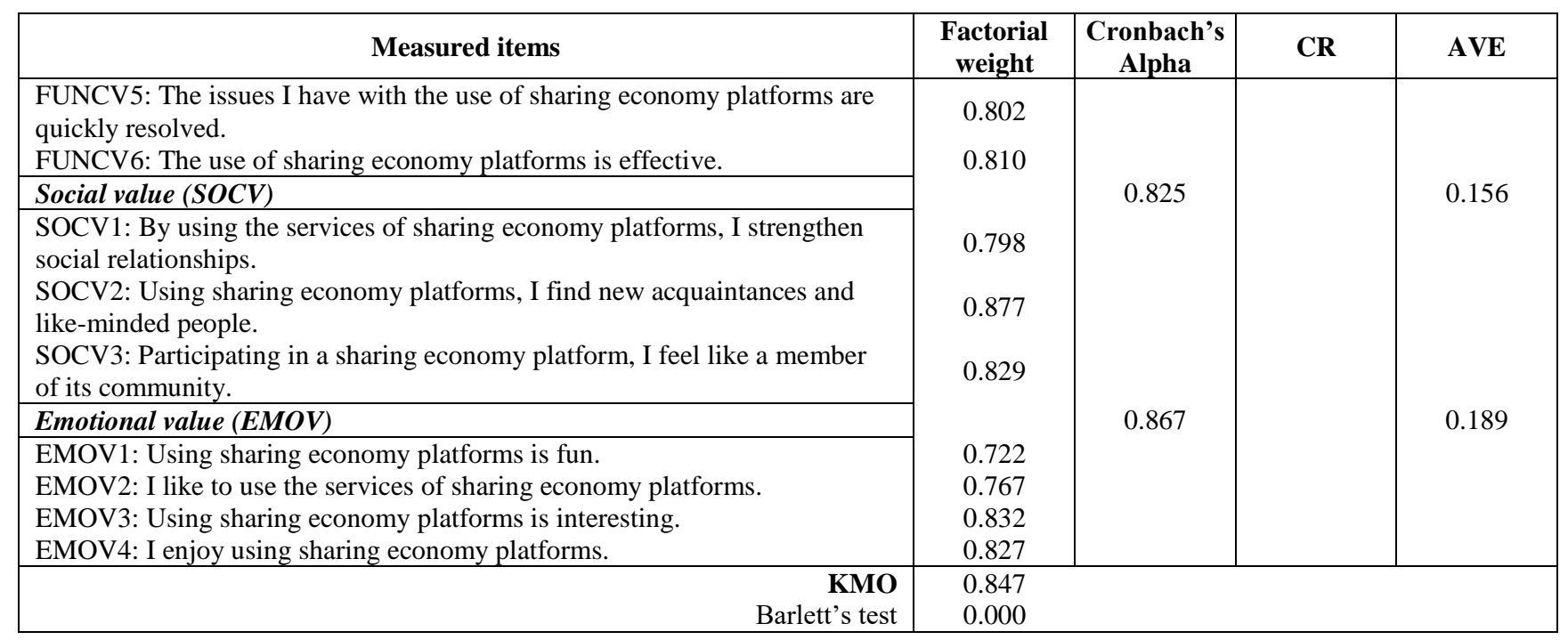

Table 3

Table 4

Construct Correlations and Square Roots of AVE

\begin{tabular}{|l|c|c|c|}
\hline \multicolumn{1}{|c|}{ Construct } & $E C$ & ATTSP & Total_value \\
\hline $\begin{array}{l}\text { Environmental } \\
\text { consciousness }(E C)\end{array}$ & 0.851 & & \\
$\begin{array}{l}\text { Attitude to sharing } \\
\text { platform (ATTSP) }\end{array}$ & 0.258 & 0.752 & 0.854 \\
$\begin{array}{l}\text { Perceived value from } \\
\text { sharing economy } \\
\text { (Total_value) }\end{array}$ & 0.210 & 0.478 & \\
\hline
\end{tabular}

Research findings. The research findings are presented in the logics of the hypotheses testing. The first part of them is devoted to the $\mathrm{H} 1$ and $\mathrm{H} 2$ testing (linear regression was applied), and the second part - for the $\mathrm{H} 3$ testing (mediation analysis was applied).

The regression models presented in Table 4 indicate that consumer environmental consciousness significantly and directly impacts social and emotional consumer perceived value from sharing economy (respectively $\beta=0.195, p=$ 0.012 and $\beta=0.267, p=0.001)$. However, $R^{2}$ values are very low, indicating that the consumer environmental consciousness very poorly describes variance of consumer perceived social and emotional value from sharing economy (see Table 4). Thus, Hypothesis H1 cannot be accepted, which indicates that other variables influence consumer perceived value from sharing economy or that the impact of consumer environmental consciousness is indirect. As regards the direct effect of consumer attitude toward sharing platform on consumer perceived value from sharing economy, the regression models indicate better results (see Table 4). This impact is confirmed in cases of economic value $\left(\beta=0.350, p<0.001 ; R^{2}=0.123, p<0.001\right)$, functional value $\left(\beta=0.390, p<0.001 ; R^{2}=0.152, p<\right.$ $0.001)$, and emotional value $\left(\beta=0.506, p<0.001 ; R^{2}=\right.$ $0.256, p<0.001)$. The insignificant direct impact is seen in the case of social value $\left(\beta=0.145, p=0.064 ; R^{2}=0.021, p\right.$ $=0.064)$. Thus, Hypothesis $\mathrm{H} 2$ is partially accepted.

\section{Regression Models for Direct Effect Analysis}

\begin{tabular}{|l|l|c|c|c|c|}
\hline $\begin{array}{c}\text { Dependent } \\
\text { variable }\end{array}$ & $\begin{array}{c}\text { Independent } \\
\text { variable }\end{array}$ & Coeff. & Sig. & $\boldsymbol{R}^{2}$ & $\boldsymbol{p}$-value \\
\hline$E C O N V$ & $E C$ & 0.130 & 0.099 & 0.017 & 0.099 \\
\hline$F U N C V$ & $E C$ & 0.143 & 0.068 & 0.021 & 0.068 \\
\hline SOCV & $E C$ & 0.195 & 0.012 & 0.038 & 0.012 \\
\hline$E M O V$ & $E C$ & 0.267 & 0.001 & 0.071 & 0.001 \\
\hline$E C O N V$ & $A T T S P$ & 0.350 & $<0.001$ & 0.123 & $<0.001$ \\
\hline FUNCV & $A T T S P$ & 0.390 & $<0.001$ & 0.152 & $<0.001$ \\
\hline SOCV & $A T T S P$ & 0.145 & 0.064 & 0.021 & 0.064 \\
\hline$E M O V$ & $A T T S P$ & 0.506 & $<0.001$ & 0.256 & $<0.001$ \\
\hline
\end{tabular}

For hypothesis $\mathrm{H} 3$ testing, SPSS PROCESS macro was applied (model 4 for the mediation analysis). It is an observed variable ordinary least squares modelling tool created by Hayes (2013). Table 5 presents all relevant regression models' results, which were needed to test the hypotheses and evaluate the direct (mediator, in this case, is considered a control variable), indirect, and the total effect of environmental consciousness on consumer perceived value from sharing economy.

Table 5

Regression Models for Mediation Analysis

\begin{tabular}{|c|c|c|c|c|}
\hline Regressors & $\rightarrow$ & Coefficient & SE & $p$-value \\
\hline \multirow{3}{*}{$X: E C$} & \multicolumn{4}{|c|}{ Dependent variable $M: A T T S P$} \\
\hline & $a \rightarrow$ & 0.2887 & 0.0755 & $<0.001$ \\
\hline & \multicolumn{4}{|c|}{$R^{2}=0.0834 ; p<0.001$} \\
\hline \multirow{4}{*}{$\begin{array}{l}X: E C \\
M: A T T S P\end{array}$} & \multicolumn{4}{|c|}{ Dependent variable $Y_{1}: E C O N V$} \\
\hline & $c_{1}{ }^{\prime} \rightarrow$ & 0.0311 & 0.0773 & 0.6880 \\
\hline & $b_{1} \rightarrow$ & 0.3415 & 0.0773 & $<0.001$ \\
\hline & & $R^{2}=0.123$ & $0<0.001$ & \\
\hline \multirow{4}{*}{$\begin{array}{l}X: E C \\
M: A T T S P\end{array}$} & \multicolumn{4}{|c|}{ Dependent variable $Y_{2}: F U N C V$} \\
\hline & $c_{2} \rightarrow$ & 0.0336 & 0.0760 & 0.6586 \\
\hline & $b_{2} \rightarrow$ & 0.3800 & 0.0760 & $<0.001$ \\
\hline & & $R^{2}=0.152$ & $0<0.001$ & \\
\hline \multirow{4}{*}{$\begin{array}{l}X: E C \\
M: A T T S P\end{array}$} & \multicolumn{4}{|c|}{ Dependent variable $Y_{3}: S O C V$} \\
\hline & $c 3^{\prime} \rightarrow$ & 0.1673 & 0.0806 & 0.0396 \\
\hline & $b_{3} \rightarrow$ & 0.0972 & 0.0806 & 0.2298 \\
\hline & & $R^{2}=0.046$ & $p<0.002$ & \\
\hline \multirow{4}{*}{$\begin{array}{l}X: E C \\
M: A T T S P\end{array}$} & \multicolumn{4}{|c|}{ Dependent variable $Y_{4}: E M O V$} \\
\hline & $c_{4}{ }^{\prime} \rightarrow$ & 0.1317 & 0.0705 & 0.0634 \\
\hline & $b_{4} \rightarrow$ & 0.4678 & 0.0705 & $<0.001$ \\
\hline & \multicolumn{4}{|c|}{$R^{2}=0.2718 ; p<0.001$} \\
\hline
\end{tabular}

Note: paths are depicted in Figure 1 
All path coefficients are visualised in the research model and presented in Figure 1. As can be seen from it, the impact of consumer environmental consciousness on consumer attitude towards sharing platforms when the mediator is controlling this relationship is statistically significant. Consumer attitude towards sharing platform affects three out of four dimensions of consumer perceived value from sharing economy. A significant effect is seen on economic value, functional value, and emotional value. Coefficients that reflect the impact of consumer environmental consciousness on perceived economic value, functional value, and emotional value as well as the influence of consumer attitude towards sharing platform on consumer perceived social value, are not significant.

We applied the bootstrapping technique in order to determine the direct and indirect effect of consumer environmental consciousness on consumer perceived value from the sharing economy through the mediation of consumer attitude towards the sharing platform. We used 5000 replications that allowed us to form $95 \%$ confidence intervals (CI) necessary to decide about the statistical significance of the analyzed influence among constructs (Hayes, 2013). The results of the mediation analysis are summarized in Table 6.

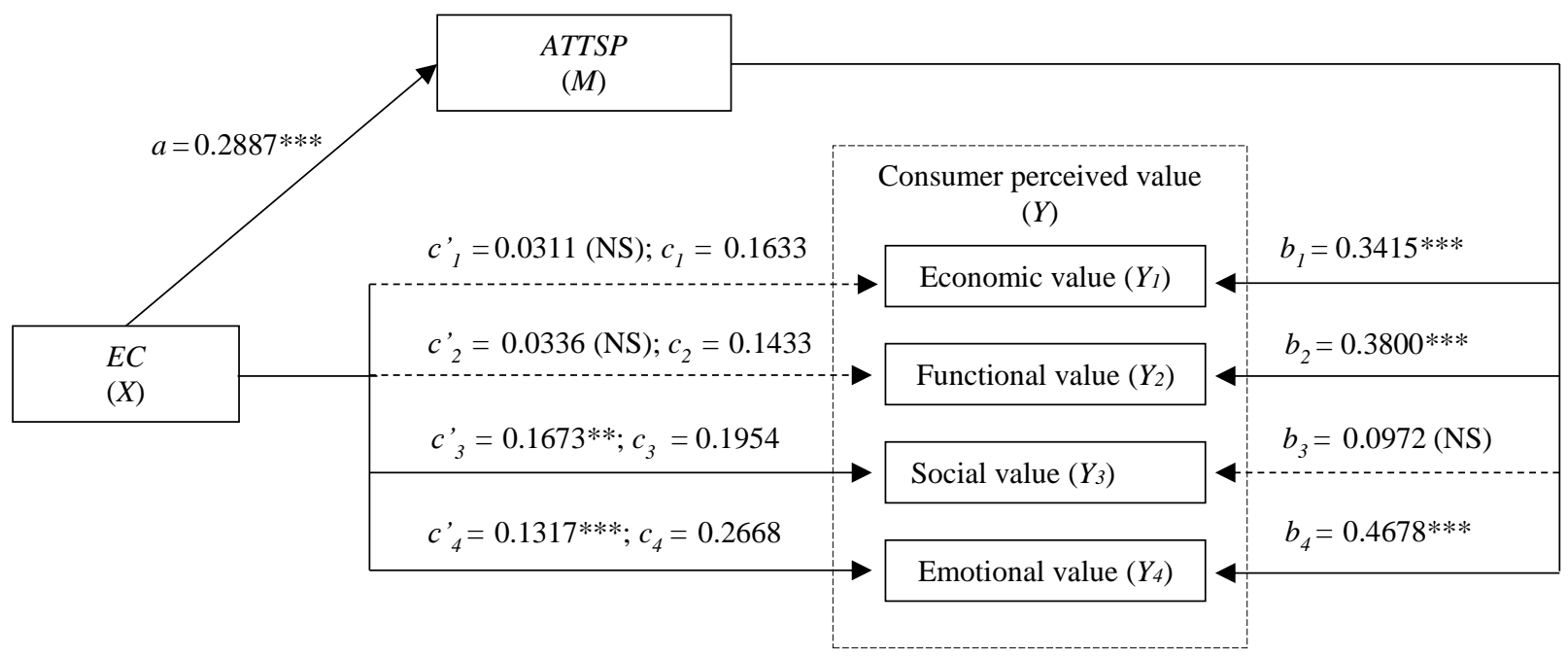

Notes: $* * * p$-value $<=0.001$; $* * p$-value $<=0.01$; (NS) not significant path

Figure 1. Research model

Table 6

Impact of Consumer Environmental Consciousness on Consumer Perceived Value from Sharing Economy: the Direct, Indirect and Total Effect

\begin{tabular}{|c|c|c|c|}
\hline \multirow{2}{*}{ Path } & \multirow{2}{*}{$\mathbf{E F} * *$} & \multicolumn{2}{|c|}{$95 \%$ confidence interval* } \\
\hline & & LLCI & ULCI \\
\hline \multicolumn{4}{|c|}{ The DIRECT effect of consumer environmental consciousness on dimensions of consumer perceived value from sharing economy } \\
\hline$E C \rightarrow E C O N V^{1}$ & 0.0311 & -0.1216 & 0.1838 \\
\hline$E C \rightarrow F U N C V^{1}$ & 0.0336 & -0.1165 & 0.1837 \\
\hline$E C \rightarrow S O C V^{1}$ & 0.1673 & 0.0080 & 0.3265 \\
\hline$E C \rightarrow E M O V^{1}$ & 0.1317 & -0.0074 & 0.2709 \\
\hline \multicolumn{4}{|c|}{$\begin{array}{l}\text { The INDIRECT effect of consumer environmental consciousness on dimensions of consumer perceived value from sharing } \\
\text { economy }\end{array}$} \\
\hline$E C \rightarrow A T T S P \rightarrow E C O N V^{2}$ & 0.0986 & 0.0340 & 0.1831 \\
\hline$E C \rightarrow A T T S P \rightarrow F U N C V^{2}$ & 0.1097 & 0.0384 & 0.1943 \\
\hline$E C \rightarrow A T T S P \rightarrow S O C V^{2}$ & 0.0281 & -0.0194 & 0.1003 \\
\hline$E C \rightarrow A T T S P \rightarrow E M O V^{2}$ & 0.1351 & 0.0563 & 0.2306 \\
\hline \multicolumn{4}{|c|}{ The TOTAL effect of consumer environmental consciousness on dimensions of consumer perceived value from sharing economy } \\
\hline$E C \rightarrow E C O N V^{3}$ & 0.1633 & - & - \\
\hline$E C \rightarrow F U N C V^{3}$ & 0.1433 & - & - \\
\hline$E C \rightarrow S O C V^{3}$ & 0.1954 & - & - \\
\hline$E C \rightarrow E M O V^{3}$ & 0.2668 & - & - \\
\hline
\end{tabular}

$* 5000$ replications were performed to form $95 \%$ bootstrapping confidence intervals.

** EF means effect.

${ }^{1} \mathrm{EF}=c_{i}$ ' where $i=1 \ldots 4$

${ }^{2} \mathrm{EF}=a b_{i}$ where $i=1 \ldots 4$

${ }^{3} \mathrm{EF}=c_{i}$ where $i=1 \ldots 4$ (sum of all effects) 
While testing Hypothesis H3, we looked at the mediation effect of consumer attitude towards sharing platforms in the relationship between consumer environmental consciousness and dimensions of consumer perceived value from the sharing economy. As shown in Table 6 , the indirect effect of consumer environmental consciousness on three out of four dimensions of consumer perceived value from sharing economy is significant. The highest indirect effect is in the case of consumer perceived emotional value from sharing economy (indirect effect $=$ $0.1351,95 \%$ CI $[0.0563 ; 0.2306])$. Consumer environmental consciousness's total effect on consumer perceived emotional value from sharing economy is also strongest $(E F=0.2668)$. Thus, Hypothesis H3 is partially accepted.

\section{Discussion and Conclusions}

Technological development and digitization are the driving forces behind the emergence and rapid growth of sharing platforms. Digital platforms and mobile apps suggesting various types of products and services from a wide range of business areas and the growth of consumers of the sharing economy are increasing every year. Such a rapid growth increases competition between sharing platforms, leading to new investigations and methods to stay in the sharing economy market. The need for sharing platforms to maintain a competitive advantage focused on retaining existing consumers and attracting new ones has increased. Understanding consumer perceived value from sharing economy can be the key to compelling competitive advantage. Although there is increasing interest in the sharing economy benefits identification and perceived value estimation, the research still lacks quantitative studies on the sharing platforms and the analysis of factors that determine consumer perceived value. In this paper, consumer perceived value was analysed through economic, functional, social, and emotional dimensions. The results show that consumer attitude towards sharing platforms is directly related to the consumer value they receive, mostly with emotional, functional, and economic values. These findings support the related research on consumer perceived value from sharing economy (Hamari et al., 2016; Butcher et al., 2016; Sung et al., 2018; Zhang et al., 2019). Consumer perceived value plays a vital role in the sharing platforms, and the suitable methods in the marketing strategy can help achieve competitive advantages.

This paper analyses environmental consciousness as a factor influencing consumer attitude towards sharing platform and indirectly affecting consumer perceived functional, economic, emotional, and social value from the sharing economy. Previous analysis of the scientific literature has shown that increasing focus on sustainability and environmental issues are crucial factors for the spread of sharing economy (Basselier et al., 2018). Sharing is considered environmentally friendly because it is assumed that it reduces the demand for new products, car sharing reduces $\mathrm{CO}_{2}$ emissions. This study confirms the direct effect of consumer environmental consciousness on consumer attitude towards sharing platforms, meaning that environmentally conscious consumers have a positive attitude towards sharing platforms. These findings support the results of the scientific research of Parguel et al. (2017) and Sands et al. (2020), which indicated environmentallyconscious consumers' greater willingness to participate in the sharing economy. Also, our findings support the statement that sharing platforms have a high sustainability potential (Bucher et al., 2016; Curtis \& Mont, 2020), and with a sustainable approach, platforms can attract more environmentally conscious consumers.

Although the first hypothesis has not been confirmed and a statistically significant relationship between environmental consciousness and consumer perceived value is not indicated, we notice an indirect relationship between environmental consciousness and social and emotional perceived value from sharing economy. So, search for likeminded people can be an important driving force in the sharing economy (Butcher et al., 2016; Sung et al., 2018; Zhang et al., 2019). Sharing platforms have a strong social impact reflecting the importance of social connections, the principle of cooperation, highlighting the benefits of making friends and getting to know each other better. Therefore, in the future, the relationship between social and emotional value and consumer environmental awareness can be explored in more depth and detail. Consequently, the consumer attitude toward sharing platforms mediates the relationship between consumer environmental consciousness and three out of four dimensions of consumer perceived value (economic, functional, and emotional) and support Moliner-Velazquez et al. (2014), Charton-Vachet et al. (2020), and Ogiemwonyi et al. (2020) findings.

\section{Managerial and Future Research Implications}

The findings of this study offer new insights into the research of consumer perceived value from the sharing economy. For managerial implication, the results of this study are useful in planning marketing strategy actions that focus on sustainability and consumer perceived value, prioritizing and emphasizing those attributes of a value proposition that establish a link between the sharing platform and environmental consciousness.

For future research, this research model can be adapted for analysing different types of sharing platforms. For example, to explore the perceived value of consumers on community-based or match-makers sharing platforms. It can also be helpful to expand the list of factors determining consumer perceived value from sharing economy and include, for example, platform reliability and usability into the research model. Moreover, our suggested research model can be expanded to study consumer future intentions related to the platforms resulting from consumer perceived value from sharing economy.

There are some limitations in this research. One limitation could be related to the sample profile, as responses were collected from Lithuanian consumers, limiting the possibility of transferring the results to other countries. For future research, it would be useful to analyse different countries and regions. Also, the Covid-19 pandemic situation may influence consumer attitude changes and usage of sharing platforms. That's why it would be purposeful to repeat the research after the pandemics and compare the findings. 


\section{References}

Acquier, A., Carbone, V., \& Masse, D. (2019). How to Create Value (s) in the Sharing Economy: Business Models, Scalability, and Sustainability. Technology Innovation Management Review, 9 (2), 5-24. http://doi.org/10.222 15/timreview/1215

Agarwal, N., \& Steinmetz, R. (2019). Sharing Economy: A Systematic Literature Review. International Journal of Innovation and Technology Management, 16 (06), 1-17. https://doi.org/10.1142/S0219877019300027

Akhmedova, A., Machuca, M. M., \& Marimon, F. (2020). Value co-creation in the sharing economy: The role of quality of service provider by peer. Journal of Cleaner Production, 266. https://doi.org/10.1016/j.jclepro.2020.121736

Basselier, R., Langenus, G., \& Walravens, L. (2018). The rise of the sharing economy. Economic Review, National Bank of Belgium, issue iii, 57-78. Available from internet: https://www.nbb.be/doc/ts/publications/economicreview/ 2018/ecoreviii2018_h3.pdf

Belk, R., (2014). You are what you can access: Sharing and collaborative consumption online. Journal of Business Research, 67 (8), 1595-1600. https://doi.org/10.1016/j.jbusres.2013.10.001

Bernardi, M., \& Diamantini, D. (2018). Shaping the sharing city: an exploratory study on Seoul and Milan. Journal of Cleaner Production, 203 30-42. https://doi.org/10.1016/j.jclepro.2018.08.132

Botsman, R., \& Rogers, R. (2010). What's Mine is Yours: The Rise of Collaborative Consumption. Harper Collins, New York.

Bucher, E., Fieseler, C., \& Lutz, C., (2016). What's mine is yours (for a nominal fee) - Exploring the spectrum of utilitarian to altruistic motives for Internet-mediated sharing. Computers in Human Behavior, 62, $316-326$. http://dx.doi.org/10.1016/j.chb.2016.04.002

Clauss, T., Harengel, P., \& Hock, M., (2018). The perception of value of platform-based business models in the sharing economy: Determining the drivers of user loyalty. Review of Managerial Science, 13, 605-634. https://doi.org/10.1007/s11846-018-0313-0

Cockayne, D. G. (2016). Sharing and neoliberal discourse: The economic function of sharing in the digital on-demand economy. Geoforum, 77, 73-82. https://doi.org/10.1016/j.geoforum.2016.10.005

Cooper, R., \& Timme, V. (2015). OneEarth. Local Governments and the Sharing Economy. Available from internet: http://www.estudislocals.cat/wp-content/uploads/2016/11/localgovsharingecon_report_full_oct2015.pdf

Charton-Vachet, F., Lombart, C., \& Louis, D., (2020). Impact of attitude towards a region on purchase intention of regional products: the mediating effects of perceived value and preference. International Journal of Retail \& Distribution Management, 48 (7), 707-725. https://www.emerald.com/insight/content/doi/10.1108/IJRDM-09-2019-0315/ full/html; https://doi.org/10.1108/IJRDM-09-2019-0315

Choi, H. R., Cho, M. J., Lee, K., Hong, S. G., \& Woo, C. R. (2014). The business model for the sharing economy between SMEs. WSEAS Transactions on Business and Economics, 11, 625-634. Available from internet: https://pdfs.semanticscholar.org/b700/6c2a885dce85e50be307308dd9944dffb296.pdf

Curtis, S. K., \& Mont, O. (2020). Sharing economy business models for sustainability. Journal of Cleaner Production, 266. DOI: https://doi.org/10.1016/j.jclepro.2020.121519

Dabbous, A., \& Tarhini, A. (2019). Assessing the impact of knowledge and perceived economic benefits on sustainable consumption through the sharing economy: A sociotechnical approach. Technological Forecasting \& Social Change, 149. https://doi.org/10.1016/j.techfore.2019.119775

European Commission (2018). Study to Monitor the Economic Development of the Collaborative Economy in the 28 EU Member States. Available from internet: https://op.europa.eu/en/publication-detail/-/publication/0cc9aab6-7501-11e89483-01 aa75ed71a1

Gurau, C., \& Ranchhod, A. (2020). The sharing economy as a complex dynamic system: Exploring coexisting constituencies, interests and practices. Journal of Cleaner Production, 245. https://doi.org/10.1016/j.jclepro.2019.118799

Hamari, J., Sjoklint, M., \& Ukkonen, A. (2016). The Sharing Economy: Why People Participate in Collaborative Consumption. Journal of the Association for Information Science and Technology, 67(9), $2047-2059$. https://doi.org/10.1002/asi.23552

Hayes, A. F. (2013). Introduction to Mediation, Moderation, and Conditional Process Analysis: a Regression-Based Approach. New York: The Guilford Press.

Hassanli, N., Small, J., \& Darcy, S. (2019). The representation of Airbnb in newspapers: a critical discourse analysis. Current Issues in Tourism, 1-13. https://doi.org/10.1080/13683500.2019.1669540

Heinrichs, H., (2013). Sharing Economy: A potential new pathway to sustainability. Ecological Perspectives for Science and Society, 22 (4), 228-231. https://doi.org/10.14512/gaia.22.4.5 
Hwang, J., \& Griffiths, M. A., (2017). Share more, drive less: Millennials value perception and behavioral intent in using collaborative consumption services. Journal of Consumer Marketing, 34 (2), 132-146. http://dx.doi.org/10.1108/JCM$10-2015-1560$

Huang, H. C., Lin T. H., Laic, M. Ch., \& Lin, T. L. (2014). Environmental consciousness and green customer behavior: Anexamination of motivation crowding effect. International Journal of Hospitality Management 40, $139-149$. http://dx.doi.org/10.1016/j.ijhm.2014.04.006

Kim, E., \& Tang, L. (2020). The role of customer behavior informing perceived value at restaurants: A multidimensional approach. International Journal of Hospitality Management, 87. https://doi.org/10.1016/j.ijhm.2020.102511

Koopman, C., Mitchell, M., D., \& Thierer, A., D. (2015). The Sharing Economy and Consumer Protection Regulation: The Case for Policy Change. The Journal of Business, Entrepreneurship \& the Law, 8 (2), 530-545. Available from internet:https://digitalcommons.pepperdine.edu/cgi/viewcontent.cgi?referer=https://scholar.google.com/\&httpsredir= $1 \&$ article $=1130 \&$ context $=\mathrm{jbel}$

Kumar, A., Prakash, G., \& Kumar, G. (2020). Does environmentally responsible purchase intention matter for consumers? A predictive sustainable model developed through an empirical study. Journal of Retailing and Consumer Services 58. https://doi.org/10.1016/j.jretconser.2020.102270

Kuo, Y., Wu, C., \& Deng, W. (2009). The relationships among service quality, perceived value, customer satisfaction, and post-purchase intention in mobile value-added services. Computers in Human Behavior, 25, 887-896. https://doi.org/10.1016/j.chb.2009.03.003

Laukkanen M., \& Tura N. (2020). The potential of sharing economy business models for sustainable value creation. Journal of cleaner production, 253. https://doi.org/10.1016/j.jclepro.2020.120004

Lee, Z., Chan, T., Balaji, M., \& Chong, A. (2018). Why people participate in the sharing economy: an empirical investigation of Uber. Internet Research, 28 (3), 829-850. https://doi.org/10.1108/IntR-01-2017-0037

Lee, S., \& Kim, D., (2018). The effect of hedonic and utilitarian values on satisfaction and loyalty of Airbnb consumers. International Journal of Contemporary Hospitality Management, 30 (3), 1332-1351. https://doi.org/10.1108/IJCHM09-2016-0504

Lock, S. (2019). Number of sharing economy users in the U.S. 2016-2021. Available from internet: https://www.statista.com/statistics/289856/ number- sharing- economy- users- us/ (accessed 13 February 2021).

Ma, Y., Rong K., Luo, Y., Wang, Y., Mangalagiu, D., \& Thornton, T. F. (2019). Value Co-creation for sustainable consumption and production in the sharing economy in China. Journal of Cleaner Production 208, 1148-1158. https://doi.org/10.1016/j.jclepro.2018.10.135

Martin, C. J. (2016). The sharing economy: a pathway to sustainability or a nightmarish form of neoliberal capitalism? Ecological Economics 121, 149-159. https://doi.org/ 10.1016/j.ecolecon.2015.11.027

Miller, D. (2019). What is the sharing economy (and how is it changing industries)? Available from internet: https://www.thebalancesmb.com/the-sharing-economy-and-how-it-changes-industries-4172234.

Moliner-Velazquez, B., Fuentes-Blasco, M., \& Gil-Saura, I. (2014).Value antecedents in relationship between tourism companies, Journal of Business and Industrial Marketing, 29 (3), 215-226. https://www.emerald.com/ insight/content/doi/10.1108/JBIM-12-2011-0179/full/pdf. https://doi.org/10.1108/JBIM-12-2011-0179

Mont, O., Palgan, V. Y., Bradley K., \& Zvolska, L. (2020). A Decade of the Sharing economy: Concepts, users, business and governance perspectives. Journal of Cleaner Production, 269. https://doi.org/10.1016/j.jclepro.2020.122215

Munoz, P., \& Cohen, B. (2017). Mapping out the sharing economy: A configurational approach to sharing business modeling. Technological Forecasting \& Soial Change, 125, 21-37. http://dx.doi.org/10.1016/j.techfore.2017.03.035

Ogiemwonyi, O., Harun, A. B., Alam A. N., \& Othman B. (2020). Do We Care about Going Green? Measuring the Effect of Green Environmental Awareness, Green Product Value and Environmental Attitude on Green Culture. An Insight from Nigeria. Environmental and Climate Technologies 24 (1), 254-274. https://doi.org/10.2478/rtuect-2020-0015

Paul J., Modi A., \& Patel J. (2016). Predicting green product consumption using theory of planned behaviour and reasoned action. Journal of Retailing and Consumer Services, 29, 123-134. https://doi.org/10.1016/j.jretconser.2015.11.006

Petrick, J., F. (2002). Development of a Multi-Dimensional Scale for Measuring the Perceived Value of a Service. Journal of Leisure Research, December, 34 (2), 119-134. https://doi.org/10.1080/00222216.2002.11949965

PwC (2015). The sharing economy: consumer intelligence series. Available from internet: https://www.pwc.com/us/en/ technology/publications/assets/pwc-consumer-intelligence-series-the-sharing-economy.pdf (accessed 19 December 2020).

PwC (2016). The sharing economy presents Europe with a $€ 570$ billion opportunity. Available from internet: https://www.pwc.com/en/en/pressroom/2016/sharing_economy_europe.html

Samdahl, M. E., \& Robertson, R. (1989). Social determinants of environmental concern: specification and test of the model. Environmental Behaviour, 21 (1), 57-81. https://doi.org/10.1177/0013916589211004 
Sands, S., Ferraro, C., Campbell, C., \& Kietzmann, J., (2020). Who shares? Profiling consumers in the sharing economy. Australian Marketing Journal, 28, 22-33. https://doi.org/10.1016/j.ausmj.2020.06.005

Schwanholz J., \& Leipold, S. (2020). Sharing for a circular economy? An analysis of digital sharing platforms' principles and business models. Journal of Cleaner Production, 269. https://doi.org/10.1016/j.jclepro.2020.122327

Seegebarth, B., Peyer, M., Balderjahn, I., \& Wiedmann, K. P., (2016). The sustainability roots of anticonsumption lifestyles and initial insights regarding their effects on consumers' well-being. The Journal of Consumers affairs, 50 (1), 68-99. https://doi.org/10.1111/joca.12077.

Shanker, A. (2012). A Customer Value Creation Framework for Businesses That Generate Revenue with Open Source Software. Technology Innovation Management Review, 18-22. Available from internet: https://timreview.ca/sites/ default/files/article_PDF/Shanker_TIMReview_March2012_0.pdf; https://doi.org/10.22215/timreview/534

Spinter research (2018). The economy of sharing: somewhere Lithuanians become Swedish. Available from internet: https://www.spinter.lt/site/lt/vidinis_noslide/menutop/9/home/publish/OTg5Ozk7OzA=

Smith, J., B., \& Colgate, M. (2007). Customer Value Creation: A Practical Framework. Journal of Marketing Theory and Practice, 15 (1), 7-23. https://doi.org/10.2753/MTP1069-6679150101

Sung, E., Kim, H., \& Lee, D. (2018). Why Do People Consume and Provide Sharing Economy Accommodation? - A Sustainability Perspective. Sustainability, 10. https://dx.doi.org/10.3390/su10062072

Zhang, T. C., Gu, H., \& Jahromi, M. F., (2019). What makes the sharing economy successful? An empirical examination of competitive value propositions. Computers in human behaviour, 95, 275-283. https://doi.org/10.1016/j.chb. 2018.03.019

Zimmer, M. R., Stafford, T. F., \& Stafford, M. R. (1994). Green issues: dimensions of environmental concern. Journal of Business Research, 30 (1), 63-74. https://doi.org/10.1016/0148-2963(94)90069-8

Wirtz, J., So, K., Mody, M., Liu, S., \& Chun, H. (2019). Platforms in the peer-to-peer sharing economy. Journal of Service Management, 30 (4), 452-483. https://doi.org/10.1108/JOSM-11-2018-0369

\section{Authors' biographies}

Agnè Gadeikienė is Ph.D. in Social Sciences (Management), is an Associate Professor in Marketing at Kaunas University of Technology, School of Economics and Business; a researcher in the research group Sustainable Management. She has broad experience as a researcher in different national and international programs' research and study projects. Her research interests are consumer behaviour, value co-creation, sustainable consumption, marketing digitalization, business models, and market research methodology. ORCID iD 0000-0001-7719-4980

Asta Švarcaitė is a Ph.D. student in Management at the Kaunas University of Technology (KTU). She is working as a Head of Administration in the Faculty of Mechanical Engineering and Design at the Kaunas University of Technology. Research interests are in consumer behavior, value co-creation, sustainable consumption, collaborative consumption, marketing digitalization. ORCID iD $\underline{0000-0001-7136-7916}$

The article has been reviewed.

Received in March 2021; accepted in October 2021.

This article is an Open Access article distributed under the terms and conditions of the Creative Commons Attribution 4.0 (CC BY 4.0) License (http://creativecommons.org/licenses/by/4.0/). 